\title{
The biodiversity hotspot as evolutionary hot-bed: spectacular radiation of Erica in the Cape Floristic Region
}

\author{
M. D. Pirie ${ }^{1,2 *}$, E. G. H. Oliver ${ }^{3}$, A. Mugrabi de Kuppler ${ }^{4}$, B. Gehrke², N. C. Le Maitre ${ }^{1}$, M. Kandziora² \\ and D. U. Bellstedt ${ }^{1}$
}

\begin{abstract}
Background: The disproportionate species richness of the world's biodiversity hotspots could be explained by low extinction (the evolutionary "museum") and/or high speciation (the "hot-bed") models. We test these models using the largest of the species rich plant groups that characterise the botanically diverse Cape Floristic Region (CFR): the genus Erica L. We generate a novel phylogenetic hypothesis informed by nuclear and plastid DNA sequences of c. $60 \%$ of the c. 800 Erica species (of which 690 are endemic to the CFR), and use this to estimate clade ages (using RELTIME; BEAST), net diversification rates (GEIGER), and shifts in rates of diversification in different areas (BAMM; MuSSE).

Results: The diversity of Erica species in the CFR is the result of a single radiation within the last C. 15 million years. Compared to ancestral lineages in the Palearctic, the rate of speciation accelerated across Africa and Madagascar, with a further burst of speciation within the CFR that also exceeds the net diversification rates of other Cape clades.

Conclusions: Erica exemplifies the "hotbed" model of assemblage through recent speciation, implying that with the advent of the modern Cape a multitude of new niches opened and were successively occupied through local species diversification.
\end{abstract}

Keywords: Biodiversity, Cape Floristic Region, Diversification, Erica, Evolution

\section{Background}

Biological diversity is spread unevenly across the globe and across the tree of life, clustered in geographic hotspots [1] and species-rich clades [2-4]. Diverse organisms with a range of life history and other traits have radiated in environments with different topographies, climates, and histories. The hyper-diverse tropical Andes set the stage for a spectacular radiation of lupins (Lupinus; Fabaceae) [2], the Amazon rainforest for that of Inga (Fabaceae) [3], the Mediterranean hotspot for that of carnations (Dianthus; Caryophyllaceae) [4] and Southern Africa's succulent karoo for that of ice plants (Ruschioideae; Aizoaceae) [5]. These species-rich groups

\footnotetext{
* Correspondence: pirie@uni-mainz.de

'Department of Biochemistry, University of Stellenbosch, Private Bag X1, Matieland 7602, South Africa

${ }^{2}$ Institut für Spezielle Botanik und Botanischer Garten, Johannes

Gutenberg-Universität, Anselm-Franz-von-Bentzelweg 9a, 55099 Mainz,

Germany

Full list of author information is available at the end of the article
}

present us with a rich and powerful source of data for bettering our understanding of the origins of biological diversity: we can analyse numerous speciation events in comparable biological systems within evolutionarily recent, and hence more tractable, timescales.

The mountainous landscape of South Africa's Cape Floristic Region (CFR) hotspot [1] hosts 9000 plant species, $70 \%$ endemic [6, 7], within only c. $90,000 \mathrm{~km}^{2}$. Thirtythree species rich "Cape clades" collectively account for around half of this remarkable richness [7], of which the genus Erica L. would be the largest, if the around 690 species [8] represent a single clade. Erica species are woody shrubs that dominate the CFR's heathland "fynbos" vegetation as well as heathland ecosystems in the western Palearctic (including the Mediterranean) and mountain "sky islands" of Tropical Africa [9] and Madagascar. However, the numbers of species in regions outside the CFR are lower by an order of magnitude. Such striking regional asymmetries in species richness within a group of notably 
consistent habit pose a fascinating evolutionary conundrum, the solutions for which can inform our general understanding of the assemblage of regional biotas.

Here we ask: a) Does the extraordinary diversity of Erica in the CFR stem from a single common ancestor in the Cape? b) Are regional asymmetries in species richness the result of shifts in rates of diversification within the Erica clade and in different areas? c) Does the radiation of Cape Erica reflect a 'museum' (low extinction) and/or 'hot-bed' (high speciation) model for the biotic assemblage of the CFR? Such an analysis demands a credible, detailed and dated phylogenetic tree of the group: we present a phylogenetic hypothesis for Erica based on greatly increased sampling of species and molecular markers.

\section{Methods}

Taxon and character sampling: Our phylogenetic hypothesis is informed by nuclear and plastid DNA sequences of c. $60 \%$ of all Erica species, represented by 606 accessions of 488 species and 28 sub-specific taxa from across the geographic range of the clade (17 of 19 Palearctic species [89\%], 414 of 690 CFR [60\%]; 13 of 23 Tropical Africa [57 \%]; 27 of 51 Drakensberg [53 \%]; and 17 of c. 41 Madagascar/Mascarenes [42\%]), plus six outgroups (Additional file 1: Table S1). Specimens were collected in the field and determined by EGHO. Vouchers were lodged in herbaria (Additional file 1: Table S1), and leaf samples dried in silica gel and archived at $-20{ }^{\circ} \mathrm{C}$ to preserve the DNA. Most sequences were obtained newly for this study, with some from previous work [10-12]. We obtained DNA sequences mostly using a direct PCR amplification protocol [13] with universal angiosperm primers $[14,15]$ as described in [12]. We employed a targeted supermatrix sampling strategy [16]: ITS and chloroplast trnT-trnL and trnLtrnF-ndhJ spacer sequences were obtained for all samples, and other plastid markers (trnL intron, atpI-atpH spacer, trnK-matK intron and matK gene, psbM-trnH spacer, $r b c L$ gene, $r p l 16$ intron, trnL-rpl32 spacer) were added for taxa selected, on the basis of preliminary analyses, as representative of early diverging lineages within each of the major subclades, in order to improve resolution of deeper nodes in the plastid tree. Sequences in general, and particularly ITS, were inspected to confirm the absence of polymorphism and (other) evidence of paralogy (e.g. indels in coding regions). An accessions table including Genbank accessions numbers is presented in Additional file 1: Table S1.

Phylogenetic inference: Individual matrices including all sequences for each marker were aligned in Mesquite [17] and imported into SequenceMatrix [18] to export concatenated matrices (excluding taxa causing topological conflict between gene trees; see below) for further analyses. A matrix of 63 phylogenetically representative taxa for which a minimum of 14 of the 20 data partitions were available was analysed using PartitionFinder [19] to infer best fitting data partitioning strategies and substitution models (heuristic search strategy 'greedy'; comparison of fit using the Bayesian information criterion). Individual markers, coding and non-coding regions within those markers, and codon positions within protein coding genes were all specified as potential data partitions. Maximum likelihood (ML) analyses were performed using RAxML on CIPRES [20, 21] incorporating the data partitions inferred using PartitionFinder. Clade support was estimated using bootstrapping halted automatically by RAxML following the majority-rule 'autoMRE' criterion. To test for experimental error, confirm congruence of individual plastid markers, and to infer and compare gene trees we performed preliminary phylogenetic analyses of individual markers separately. These were followed by final analyses of ITS, combined plastid data and combined ITS and plastid data. Fifteen taxa causing topological conflict subject to $\geq 70 \%$ bootstrap support (BS) between ITS and combined plastid gene trees were excluded from analyses of the concatenated data (leaving 597) under the assumption that such conflicts reflect (apparently uncommon) incidences of reticulation or incomplete lineage sorting that violate the assumption of a bifurcating tree [22]. Further phylogenetic analyses were performed using BEAST 1.8 [23] (as below).

Molecular dating: Two dating methods were employed on the Ericeae matrix: BEAST [23], using the 63 taxa matrix but excluding the most distant outgroup, Empetrum; and RELTIME [24], using the 597 taxa ML tree from the RAxML concatenated data analysis, removing Empetrum and Corema album. We used the 63 taxa matrix with BEAST because of the failure of multiple runs to converge with the full supermatrix, a not unexpected phenomenon in the presence of large proportions of missing data [16]. The targeted sampling strategy meant that the same internal focal nodes are represented in both trees. For BEAST, the root age (most recent common ancestor of Erica and Daboecia) was constrained based on the results of [25] in Ericaceae-wide analyses employing multiple fossil calibrations (producing results consistent with those presented in [26]). We used a normal distribution with mean 62 Mya and SD 10, giving a $95 \%$ prior probability distribution of 42-82 Mya reflecting uncertainty in the original analyses [25]. In a further analysis an additional prior was implemented to reflect the age of Ericaceae pollen in sediments offshore of Southern Africa [27] and thereby test the impact on age estimates assuming that this pollen record represents Erica. For this, we used an exponential distribution with offset of 10 Mya (a hard minimum) and mean of 2.0 , giving a $95 \%$ prior probability distribution of $10-16$ 
Mya (i.e. a soft maximum) for the stem node of Cape Erica. This is to assume that the Cape Erica clade is at least as old as the age of the pollen record and may be older to a limited degree. Following preliminary partitioned analyses that failed to converge, the data were not partitioned; we applied a GTR + G substitution model, lognormal relaxed clock, Yule process speciation model, and otherwise default priors, and performed two runs of 10 million generations sampling every 1000 in each case. Convergence was assessed using TRACER 1.6 [28] and Are We There Yet [29], and the results summarised using programs of the BEAST package. For RELTIME we assumed local clocks and imposed age constraints by means of a point estimate for the root node (the minimum, mean and maximum ages as above).

Diversification rates analyses: To infer the net diversification rate of the Erica Cape clade and compare it to those of other Cape and rapidly radiating clades, we used the method of Magallón \& Sanderson ([30], as implemented in GEIGER; [31]). For Cape Erica, we used species richness and full range of crown node ages (minimum and maximum under RELTIME and highest posterior density intervals under BEAST) as inferred here. For comparison, we performed the same calculations based on data from the literature for the recent rapid radiations of lupins [2], Inga [3], carnations [4], and ice plants [5]; as well as the Cape clades Muraltia [32], Pentameris [33] Protea [34] and Restionoideae ("African Restionaceae") [32]. The latter are examples for which detailed time-calibrated phylogenies of ancestrally CFR species - not those that also diversified in other areas - are available. We did not account for the impact on crown node age estimates of unsampled species during the calculation, and used relative extinction rates of 0.9 and zero across the board.

To test whether diversification rate heterogeneity reflects different speciation and extinction rates between geographic areas, we used MuSSE (Multiple State Speciation and Extinction) as implemented in diversitree 0.93 [35]. MuSSE uses maximum likelihood to estimate the values of different parameters under a constant birth death model: speciation $(\lambda)$ and extinction $(\mu)$ rates under each of the discrete states of the character (in this case, geographic distribution), and rates of transition (q) from one state (area) to another. We compared the rates between Palearctic, Tropical African, Madagascan, Drakensberg and Cape species of Erica, Calluna and Daboecia. The areas are indicated in Fig. 1 and were so defined because they are often compared in the literature, are largely geographically isolated and $<1 \%$ of Erica species are widespread between any two of them (these limited to two species in both the Cape and Drakensberg - E. caffra and E. cerinthoides - and one in the Palearctic and Tropical Africa $-E$. arborea). We used the discrete multistate model, instead of GeoSSE, that models widespread geographic distributions, to represent multiple areas (rather than just two in GeoSSE) under the assumption that widespread distributions were rare throughout the evolutionary history of the group. We coded the three samples of widespread species according to the region in which they were collected under the assumption that effectively failing to sample such species across their wider distribution would have little impact on the results. We used the rate-smoothed 597 taxa RAxML tree, having removed multiple accessions of species and outgroups (leaving 487 terminals), and corrected for incomplete sampling by assigning regionspecific sampling fractions. We did not consider phylogenetic uncertainty, as the major clades are well supported and largely restricted to single regions and thus the uncertainty regarding our question remains low. We compared maximum likelihood estimates given models considering different regions (either 5 distinct regions or combinations of Palearctic, Cape and the rest of Africa or of Europe versus Africa and or Cape versus other regions) and considering single versus multiple rates for speciation and/or extinction. For all but the unconstrained model, we constrained the transition rates to one parameter. Thereafter, for the best model, we tested whether constraining the transition rate reduces the likelihood. We compared the fit of the models to the data using the anova function in diversitree and using the AIC to compare the fit of the models. The parameters for the best fitting model were then calculated using a Bayesian MCMC approach run for 10,000 steps using an exponential probability distribution as prior for the underlying rates in the model. We assessed convergence by comparing the probability values of the sampling after excluding a burnin of $25 \%$.

To further determine whether there is diversification rate heterogeneity in the Erica dataset, we used BAMM 2.5 and Bammtools 2.1 [36, 37]. The method compares the fit of different models (a series of diversification processes) assuming different numbers of shifts based on a reversible jump MCMC to explore parameter space. We used the pruned, rate-smoothed RAxML tree, as above, and corrected for non-random species sampling by assigning regional specific proportions to the few, largely endemic, clades. We used "setBAMMpriors" to adjust the priors according to the scaling of the tree. The initial speciation rate was set to 0.18 and extinction rate to 0.111 according to inferred rates for Ericaceae [25]. Preliminary results showed that different initial speciation and extinction rate did not have a large effect on our results. The MCMC was run for 10,000,000 generations, with every 1000 generation saved. To assess convergence, the likelihood of all sampled generations was plotted in R (burnin $=10 \%$ ) and ESS values for the 


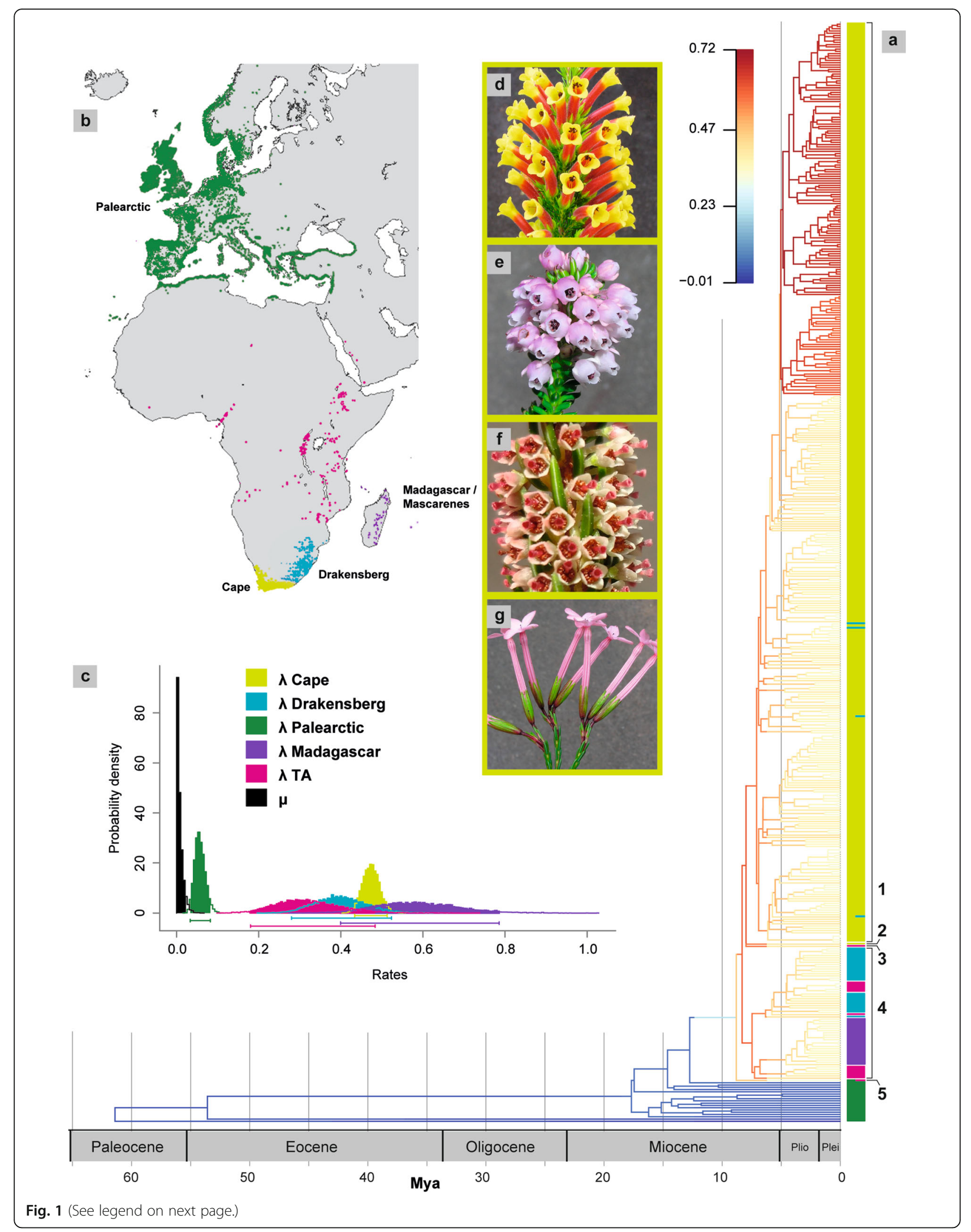


(See figure on previous page.)

Fig. 1 The diversification of Erica in space and time. a Time-calibrated phylogenetic tree of 478 extant lineages that populated the radiation of Erica with branches coloured according to mean net diversification rates (scale indicates species per million years) inferred using BAMM, with regions of samples indicated by the coloured bar at the terminals and clades/species referred to in the text indicated with numbers: $1=$ Cape clade; $2=E$. pauciovulata; $3=E$. trimera; 4 = Afrotemperate clade; $5=$ E. arborea. b Geographic distribution of Erica, based on collections databased by GBIF, showing Palearctic, Tropical Africa, Madagascar, Drakensberg and Cape regions. c Region specific speciation rates $(\lambda)$ and the single extinction rate $(\mu)$. $\mathbf{d}$-g Examples of the spectacular floral diversity of Cape Erica: d) E. macowanii, e) E. pulvinata, f) E. coarctata, and g) E. jasminiflora

likelihood and the inferred numbers of shifts were calculated using the coda package [38]. It was not possible to compare Bayes Factors for zero rate shifts with those for given numbers of shifts (see BAMM Documentation part 7.6), but we compared the prior probability of a given number of shifts to the posterior probability to confirm that these differed. We then computed the set of credible shifts and reconstructed the mean of the marginal posterior density of speciation, extinction and net diversification rates across the tree. We sought to assess whether the BAMM results are dependent on the particular topology and branch lengths of the phylogenetic tree used above by repeating the analyses with 25 randomly selected, rate smoothed and pruned RAxML bootstrap trees.

\section{Results}

Results of preliminary analyses of individual plastid markers (TreeBase study accession URL: http://purl.org/ phylo/treebase/phylows/study/TB2:S18291) showed no conflicting nodes supported at $\geq 70 \%$ bootstrap support (BS). The better resolved combined plastid gene tree (Additional file 2: Figure S1a) was largely consistent with that of ITS (Additional file 2: Figure S1b). Fifteen taxa causing topological conflict subject to $\geq 70 \%$ BS between ITS and combined plastid gene trees (indicated in Additional file 2: Figures S1a and b) were excluded from analyses of the concatenated data (leaving 597; Additional file 2: Figure S1c). Further exclusion of one Cape species, $E$. pauciovulata, resulted in an increase in support for a single Cape clade (see below) from 70 \% BS (Additional file 2: Figure S1c) to 89 \% (Additional file 2: Figure S1d).

The Erica phylogeny roots in a northern Palearctic grade subtending a southern African/Madagascan clade. The latter comprises a deep polytomy including a) the Cape clade, including all but one Cape species plus four found in the Drakensberg (two of which also distributed in the Cape), b) a single further Cape species, E. pauciovulata, c) E. trimera (Tropical Africa), d) the 'Extra-CFR African clade' that includes all other Drakensberg and Tropical African species (except for E. arborea) and a clade of all Madagascan/Mascarene species, and e) E. arborea (Palearctic and TA) (Fig. 1, Additional file 2: Figure S1). Our age estimates for clades within Erica (Fig. 1, Additional file 3: Figure S2a-c) are based on the similar results of both the two relaxed clock molecular dating methods (RELTIME, Additional file 3:
Figure S2a; and BEAST, Additional file 3: Figure S2b) with secondary calibration, and additional BEAST results (Additional file 3: Figure S2c) further constrained using the Southern Africa offshore microfossil record. The crown node of Erica was estimated at 18 (24-12) Mya (RELTIME on the matrix of 597 taxa; Additional file 3: Figure S2a) and 27-19/31-12 Mya (95 \% posterior probability ranges from BEAST, using the reduced matrix of 62 taxa, with/without microfossil evidence; Additional file 3: Figure S2b/c). The radiation of lineages within the African/Madagascan clade was estimated at 9 (12-6) Mya (RELTIME) and 14-11/17-7 Mya (BEAST). The stem node of the Cape clade was estimated at 8 (11-6) Mya (RELTIME) and 12-10/15-6 Mya (BEAST); the crown node at 7 (9-5) Mya (RELTIME) and 11-9/15-6 Mya (BEAST).

Given our dated phylogenetic trees, the net diversification rate of Cape Erica was 0.28-0.7 (assuming relative extinction of 0.9 ) or $0.39-0.97$ (relative extinction zero) species per million years; estimated rates of other Cape clades and faster recent species radiations reported worldwide are presented in Table 1.

MUSSE analyses performed with diversitree identified differences in speciation rates specific to geographic regions, with the best scoring model otherwise including only single rates for extinction and for transitions (dispersals between regions; Table 2). The lowest diversification rate is in the Palearctic, while rates in all other regions are high (Fig. 1c; Table 3). Three further models scored within $\leq 2$ of the best model according to the AIC (Table 2); these included single rates for transitions, either five or two parameters for region-specific speciation rates (the latter, Palearctic versus Africa) and two differing rates for extinction (either Palearctic versus Africa or Cape versus all other areas; Additional file 4: Table S2). The inferred rates for extinction were universally similar and low (Additional file 4: Table S2)

BAMM analyses also indicated strong support for heterogeneous diversification dynamics within Erica, in the form of multiple accelerations in the rate of diversification (Figs. 1 and 2, Additional file 5: Figure S3a; posterior probability $[\mathrm{PP}]$ of a single rate model $=0$; PP density of 2-4 rate shifts $=0.74 ; 2-5$ rate shifts $=0.87$; Additional file 5: Figure S3b). Extinction rates appear to be constant through time, but speciation rates vary greatly. We inferred 14 distinct configurations within the $95 \%$ credible shift sets. Distinct diversification regimes were associated 
Table 1 Plant diversification rates in the CFR and beyond. Net diversification rates of Cape clades and other recent radiations worldwide in species per million years, estimated using species numbers and clades ages with the method of S Magallón and MJ Sanderson [30]

\begin{tabular}{|c|c|c|c|c|c|c|}
\hline Clade & Species numbers & Crown age (Mya) & Reference & $\begin{array}{l}\text { Rate (Species/Mya) relative } \\
\text { extinction }=0.9\end{array}$ & $\begin{array}{l}\text { Rate (Species/Mya) relative } \\
\text { extinction }=0.0\end{array}$ & Note \\
\hline \multicolumn{7}{|l|}{ Cape clades: } \\
\hline Cape Erica & 690 & $6.0-15.0$ & This paper & $0.28-0.70$ & $0.39-0.97$ & $\begin{array}{l}\text { Range of estimates from RELTIME } \\
\text { and BEAST analyses }\end{array}$ \\
\hline Muraltia & 124 & $8.6-16.4$ & [32] & $0.15-0.29$ & $0.25-0.48$ & Presented range (molecular dating) \\
\hline Restionoideae & 350 & $31.7-65.4$ & [32] & $0.05-0.11$ & $0.07-0.16$ & Presented range (molecular dating) \\
\hline Pentameris & 83 & $13.2-16.1$ & [33] & $0.13-0.16$ & $0.23-0.28$ & Presented range (molecular dating) \\
\hline Protea & 69 & $11.2-27.2$ & [34] & $0.07-0.18$ & $0.13-0.32$ & Presented range (molecular dating) \\
\hline \multicolumn{7}{|l|}{ Other clades: } \\
\hline \multirow[t]{2}{*}{ Andean lupins } & \multirow[t]{2}{*}{85} & $1.6-2.3$ & [2] & $0.96-1.38$ & $1.64-2.37$ & Lupinus stem calibrated at 21.16 Ma \\
\hline & & $1.2-1.8$ & As above & $1.24-1.86$ & $2.13-3.18$ & Lupinus stem calibrated at $16.01 \mathrm{Ma}$ \\
\hline \multirow{2}{*}{$\begin{array}{l}\text { Ice plants (Aizoaceae: } \\
\text { Ruschioideae) }\end{array}$} & \multirow[t]{2}{*}{1563} & $0.6-7.0$ & [5] & $0.28-3.32$ & $0.5-5.88$ & Calibrated with ITS substitution rates \\
\hline & & $8.0-9.4$ & As above & $0.53-0.63$ & $0.71-0.83$ & Calibrated with plastid substitution rates \\
\hline European Dianthus & 200 & $0.61-2.4$ & [4] & $1.23-4.90$ & $1.9-7.55$ & Min. and max. ages reported \\
\hline Inga & 300 & $1.6-9.8$ & [3] & $0.34-2.11$ & $0.51-3.13$ & Calibrated with trnL-F/ITS substitution rates \\
\hline
\end{tabular}


Table 2 Comparison of different MuSSE models estimated for 478 species of Erica

\begin{tabular}{|c|c|c|c|c|c|c|c|c|}
\hline Geographical regions & constraints & No. of $\lambda$ parameters & No. of $\mu$ parameters & No. of q parameters & InLik & $\mathrm{AIC}$ & AIC weights & Parameter estimates \\
\hline \multirow{4}{*}{$\begin{array}{l}\text { Palearctic, Cape, } \\
\text { Drakensberg, } \\
\text { Madagascar, } \\
\text { Tropical Africa }\end{array}$} & - & 5 & 5 & 20 & -1048.9 & 2157.7 & $6.056120 \mathrm{e}-06$ & \multirow{8}{*}{ Table 3} \\
\hline & $\lambda, q$ & 1 & 5 & 1 & -1082.9 & 2179.8 & $9.621447 \mathrm{e}-11$ & \\
\hline & $\mu, q$ & 5 & 1 & 1 & -1060.8 & 2135.5 & $4.007405 e-01$ & \\
\hline & $\mu$ & 5 & 1 & 20 & -1051.3 & 2154.7 & $2.714164 \mathrm{e}-05$ & \\
\hline One region & $\lambda, \mu, q$ & 1 & 1 & 1 & -1162.5 & 2331.0 & $6.040484 \mathrm{e}-05$ & \\
\hline \multirow{3}{*}{$\begin{array}{l}\text { Palearctic, Cape, } \\
\text { rest of Africa }\end{array}$} & $\lambda, q$ & 3 & 5 & 1 & -1062.4 & 2142.8 & $1.041570 \mathrm{e}-02$ & \\
\hline & $\mu, q$ & 5 & 3 & 1 & -1060.8 & 2139.5 & 5.423432e-02 & \\
\hline & $\lambda, \mu, q$ & 3 & 3 & 1 & -1063.3 & 2140.6 & $3.129048 \mathrm{e}-02$ & \\
\hline \multirow[t]{3}{*}{ Palearctic, Africa } & $\lambda, q$ & 2 & 5 & 1 & -1062.4 & 2140.8 & $2.831280 \mathrm{e}-02$ & \\
\hline & $\mu, q$ & 5 & 2 & 1 & -1060.8 & 2137.5 & $1.474242 \mathrm{e}-01$ & Additional file 4: Table S2, Model 1 \\
\hline & $\lambda, \mu, q$ & 2 & 2 & 1 & -1063.6 & 2137.1 & $1.800643 \mathrm{e}-01$ & Additional file 4: Table S2, Model 2 \\
\hline \multirow[t]{3}{*}{ Cape, other } & $\lambda, q$ & 2 & 5 & 1 & -1081.1 & 2178.1 & $2.251079 \mathrm{e}-10$ & \\
\hline & $\mu, q$ & 5 & 2 & 1 & -1060.8 & 2137.5 & $1.474242 \mathrm{e}-01$ & \multirow[t]{2}{*}{ Additional file 4: Table S2, Model 3} \\
\hline & $\lambda, \mu, q$ & 2 & 2 & 1 & -1100.9 & 2211.7 & $1.138265 \mathrm{e}-17$ & \\
\hline
\end{tabular}

Abbreviations: $\lambda$ - speciation rate, $\mu$ - extinction rate, q - transition rate, InLik - logarithm of likelihood, AIC - Akaike information criterion. The best scoring model is indicated with bold italics (parameter estimates presented in Table 3); three models with AIC scores within 2 of the best scoring model are indicated in bold (parameter estimates presented in Additional file 4: Table S2) 
Table 3 Parameter estimates given the best scoring MuSSE model

\begin{tabular}{lcccccccc}
\hline & $\lambda$ Cape & $\lambda$ Drakensberg & $\lambda$ Palearctic & $\lambda$ Madagascar & $\lambda$ TA & $\mu$ & transition rate & $p$ \\
\hline Min. & 0.4043 & 0.1971 & 0.01685 & 0.2771 & 0.1013 & $2.20 \mathrm{E}-7$ & $2.39 \mathrm{E}-4$ & -1074 \\
1st Qu. & 0.4595 & 0.3575 & 0.04795 & 0.5179 & 0.2658 & $2.24 \mathrm{E}-3$ & $1.15 \mathrm{E}-3$ & -1064 \\
Median & 0.4734 & 0.3978 & 0.05598 & 0.5818 & 0.3149 & $5.37 \mathrm{E}-3$ & $1.43 \mathrm{E}-3$ & -1062 \\
Mean & 0.4735 & 0.4002 & 0.0569 & 0.5869 & 0.3216 & $7.65 \mathrm{E}-3$ & $1.49 \mathrm{E}-3$ & -1062 \\
3rd Qu. & 0.4872 & 0.4402 & 0.06498 & 0.6527 & 0.3702 & $1.08 \mathrm{E}-2$ & $1.77 \mathrm{E}-3$ & -1061 \\
Max. & 0.5536 & 0.6644 & 0.11022 & 1.0282 & 0.7366 & $6.40 \mathrm{E}-2$ & $3.85 \mathrm{E}-3$ & -1059
\end{tabular}

with the Erica clade, the African/Madagascan clade (either including E. arborea, or not) and within the Cape clade; the former is found in only four of the nine configurations with highest PP which together sum to PP $>0.90$ (Fig. 2) (and generally fewer than half of each of the individual configurations based on 25 bootstrap trees), whilst the two latter shifts are found in all of them (the African/ Madagascan clade shift in almost all, and the shift within the Cape clade generally in more than half of the individual bootstrap configurations; Additional file 6: Table S3).

\section{Discussion}

Whilst the richness of Erica species in the CFR is renowned, our results can finally confirm Erica as the most species rich Cape clade. With the possible exception of a single anomalous species (E. pauciovulata), all Erica in the CFR that we analysed can be traced back to a single common ancestor that colonised the region no earlier than c. $15 \mathrm{Mya}$, and all but a handful are endemic (Fig. 1). A Late Miocene initiation of the Erica radiation in the CFR is consistent with the first appearance of

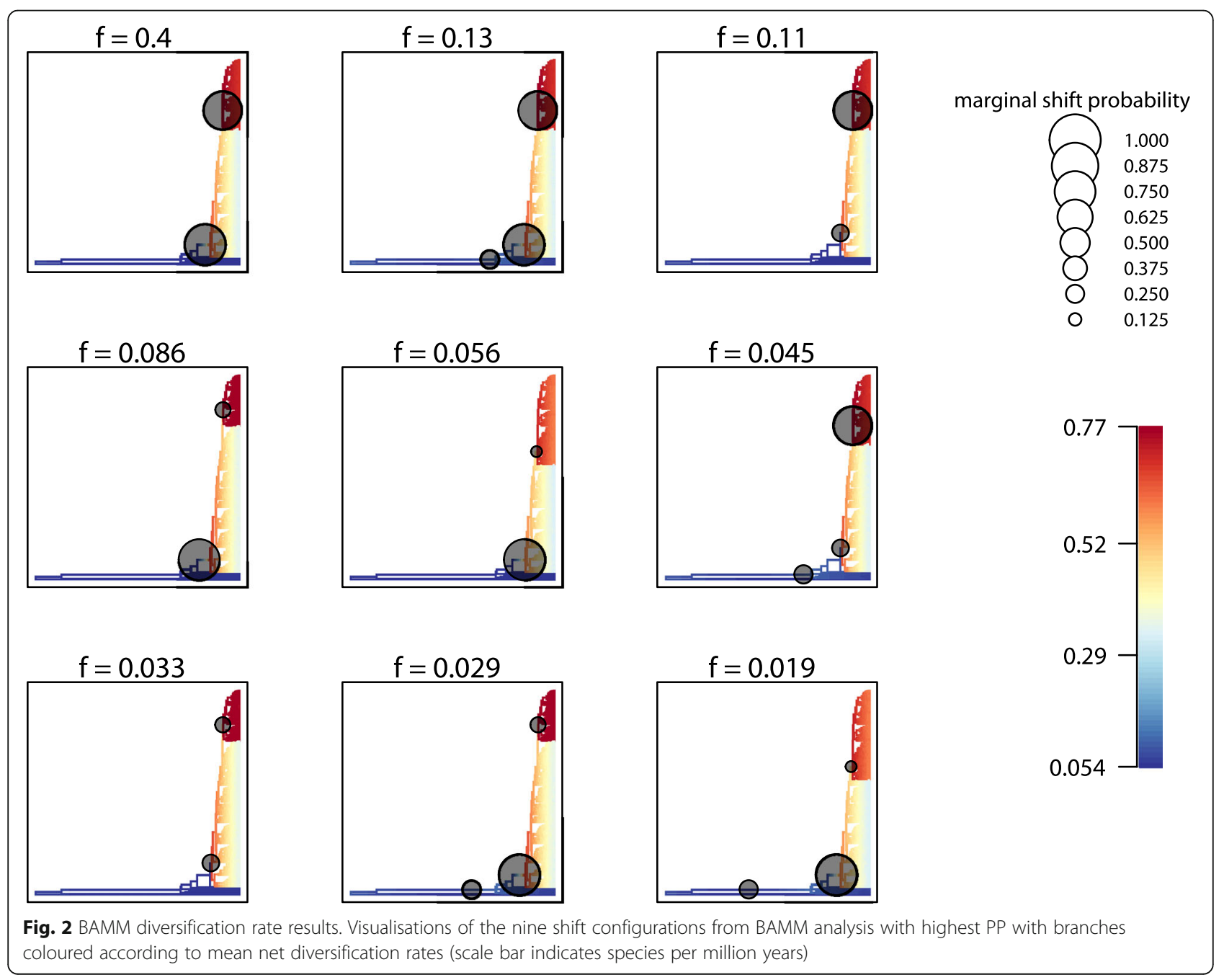


pollen of Ericaceae (and various other typical fynbos groups) in the fossil record in Southern Africa after 10 Mya [27]. Cape clades differ widely in age [39], and Cape Erica is neither conspicuously old nor young in this context. Its net diversification rate is modest compared to the most spectacular examples in flowering plants, documented from the much greater areas of the Andean Páramo [2] and the Mediterranean [4]. The Erica diversification rate is more similar to those of other rapidly evolving Cape clades, although notably faster than any that we compared (Table 1).

This remarkable radiation of Erica in the CFR is in stark contrast to the comparatively impoverished older Palearctic lineages. The heathers originated in the Northern Hemisphere [10, 12] and northern lineages (including monotypic Calluna and two species of Daboecia) are older than the single southern Erica clade ('African/Malagasy Erica'; [10]). Higher diversity in Cape compared to Mediterranean clades has been attributed to lower rates of extinction [40]. Our results instead imply slower speciation in the wider western Palearctic (Fig. 1; Table 3 and Additional file 4: Table S2), although this conclusion must be qualified by the known difficulty of inferring extinction rates from molecular phylogenies [41]. Although the ranges of speciation (and hence net diversification) rates in different regions outside the Palearctic overlapped (perhaps a methodological artefact caused by the much lower species numbers outside the Cape [42]), we discovered evidence for a rate increase within the Cape clade (Figs. 1 and 2). Phylogenetic uncertainty within the Cape clade is considerable (reflecting the short internal branches typical of bursts of lineage diversification [37]), but geographically, this diversification centres on lineages of the large SW-clade [10] mostly restricted within the South-Western CFR. Irrespective of inferred shifts in diversification rates, the greater areas of equivalent habitat in Tropical Africa and the Drakensberg (for similarly distributed Protea, estimated at roughly 17-fold; [34]) and in Madagascar compared to the CFR represent far lower densities of species and of speciation events through time given the phylogeny and clade ages inferred here.

The CFR is one of a number of mountainous and Mediterranean climate regions with unique and hyperdiverse biotas that both coincidentally, and as the result of worldwide climatic changes, originated within similar, relatively recent timeframes $[2,25,40,43]$. The modern CFR was shaped by globally influenced palaeoclimatic dynamics that established during the Miocene, particularly world-wide cooling that led to aridification [44], and the establishment of the cold Benguela current off the south-west African coast, that led to the development of a winter rainfall regime and frequent fires $[45,46]$. The disappearance of more mesic tropical forest elements from fossil deposits [27, 47] was followed by the appearance of more arid and/or fire adapted elements such as Aizoaceae, including Ruschioideae (in the succulent karoo), and Erica (in the CFR) [27]; the latter with its reduced leaf area and resistant yet inflammable wax-rich cuticles [48] combined with post-fire re-sprouting and smoke-stimulated reseeding recruitment strategies $[49,50]$.

As with other mountainous hotspots [43], the CFR was also influenced by local uplift, that occurred during the Miocene $[51,52]$. The high species richness and local endemism of the present day Cape is plausibly a direct result of this uplift: new niches opened, with physical barriers to gene flow between them, creating a stimulus for allopatric speciation [53]. Topographical complexity also creates local temperature and moisture gradients [53], and the patchwork of soils derived from the different lithologies of the Cape [54, 55] adds a further dimension to the resulting fine-scaled mosaic of habitats. By contrast to regions of the Northern Hemisphere, the Cape was buffered from the extremes of Pleistocene glacial cycles, and by implication from resulting extinction [56]; instead (less extreme) shifts in multiple local-scale ecological gradients, acting in concert, might actually drive speciation [57]. Key innovations in particular groups are also often mooted, such as adaptations to specialised pollinator interactions [58] that might reinforce speciation [59]. The numerous apparent shifts in pollination syndrome in Erica and the higher diversity of different syndromes in Erica in the Cape than elsewhere [10] make the latter a tempting explanation for the acceleration of the Cape Erica radiation.

However, meta-analyses of Cape phylogenies have provided support for multiple such hypotheses, with evidence for both ecological and/or pollinator shifts [60] and distributional and phenological shifts [61] in e.g. Muraltia, Cape Restionaceae and Pentameris; each of these and others too (such as edaphic shifts apparent in Babiana (Iridaceae) [62]) may have played a role. Given the results presented here, it is also plausible that (combinations of) factors specific to the most species-rich SW region may be responsible for the highest rates of diversification within the CFR. The relative contribution of these different factors overall is still hotly debated, and with a phylogenetic hypothesis for the clade now available, Cape Erica offers the greatest single source of data for further testing their importance in the assemblage of the flora.

\section{Conclusions}

In two contrasting perspectives, the CFR is interpreted as a 'museum' of diversity [63], with persistence of preMiocene lineages [64] and lower extinction e.g. compared to the Mediterranean [40]; or the evolutionary 'hot-bed' of (recent) radiations [32, 39, 65, 66]. These models are not mutually exclusive $[39,67]$. However, our results further 
weigh the balance in favour of the latter. The largest Cape clade, Erica, represents more species than included in most meta-analyses of Cape clades performed to date. Much of this remarkable diversity originated within the last few million years.

\section{Additional files}

Additional file 1: Table S1. Accessions table including Genbank accession numbers. (XLSX $119 \mathrm{~kb}$ )

Additional file 2: Figure S1. Phylogenetic hypotheses: best trees with bootstrap support values from RAxML analyses of a) concatenated plastid data and b) from nuclear ribosomal ITS (with taxa showing conflicting positions according to the two gene trees highlighted in yellow); and c) and d) of the combined data (excluding conflicting taxa): c) with and d) without Erica pauciovulata (exclusion of which leads to increased support for the Cape clade from $70 \%$ to $89 \%$ ). (ZIP $8409 \mathrm{~kb}$ )

Additional file 3: Figure S2. Relaxed clock molecular dating results: a) age estimates for clades within Erica inferred using RELTIME [24] with the best tree from RAxML (Additional file 2: Figure S1c); b) and c) phylogeny and relaxed clock molecular dating age estimates for clades within Erica inferred using BEAST [23] on a reduced matrix of 62 taxa b) with and c) without additional constraint based on microfossil evidence (error bars represent 95 \% Posterior Probability (PP) intervals; PP clade support is indicated at nodes). (ZIP $11562 \mathrm{~kb}$ )

Additional file 4: Table S2. Parameter estimates given the three best scoring suboptimal MuSSE models. (DOCX $15 \mathrm{~kb}$ )

Additional file 5: Figures S3. BAMM diversification rate results: a) BAMM tree as presented in Fig. 1, including labels for tips and nodes referred to in the text; branches subtending Erica, Calluna and Daboecia are not to scale. b) Probabilities of overall numbers of diversification shifts inferred using BAMM. (ZIP 2444 kb)

Additional file 6: Table S3. Summary of BAMM results based on 25 rate-smoothed RAXML bootstrap trees. (DOCX $12 \mathrm{~kb}$ )

\section{Acknowledgements}

We thank F.P.D. Cotterill, T. van der Niet and J.W. Kadereit for comments on drafts of the paper; D. Franke for assistance with graphics; J. Fagúndez, A. Hitchcock, R. Turner, M. Muasya, C. Stirton, R. Clark, B. Bytebier, M. Pimentel, F. Ojeda, C. Merry, and many others for providing samples; and Cape Nature and South Africa National Parks for assistance with permits. The authors gratefully acknowledge the computing time granted on the supercomputer Mogon at Johannes Gutenberg University Mainz (https://hpc.uni-mainz.de/)

\section{Funding}

South African National Research Foundation (NRF; DUB and MDP); a postdoctoral fellowship from the Claude Leon Foundation (MDP); DFG (PI1169/1-1 to MDP); and the Ministerium für Klimaschutz, Umwelt, Landwirtschaft, Natur- und Verbraucherschutz des Landes NordrheinWestfalen, the Faculty of Agriculture Lehr- und Forschungsschwerpunkt "Umweltverträgliche und Standortgerechte Landwirtschaft", Bonn University; and the Landgard foundation (AMK). Any opinion, finding and conclusion or recommendation expressed in this material is that of the authors and the NRF does not accept liability in this regard.

\section{Availability of data and material}

DNA sequence data presented here will be available on publication from Genbank (accession numbers KU831550-KU833209 and KU863006-KU863021) and matrices and phylogenetic trees from TreeBase (study accession URL: http://purl.org/phylo/treebase/phylows/study/TB2:S18291).

\section{Authors' contributions}

DUB, MDP \& EGHO planned and designed the research; EGHO, MDP, BG and DUB conducted fieldwork; EGHO identified specimens; NLM, AMK \& MDP: performed lab work; MDP \& MK: analysed data; and MDP led the writing (to which all authors contributed). All authors read and approved the final manuscript.

\section{Authors' information}

MDP \& BG are research associates/lecturers, and MK received her PhD (2015), at the Johannes Gutenberg-Universität, Mainz, Germany; MDP and EGHO are honorary research Associates, NLM PhD student, and DUB full professor, at the University of Stellenbosch, South Africa; and AMK received her PhD (2013) at the University of Bonn, Germany.

\section{Competing interests}

The authors declare that they have no competing interests.

\section{Consent for publication}

Not applicable.

Ethics approval and consent to participate

Not applicable.

\section{Author details}

'Department of Biochemistry, University of Stellenbosch, Private Bag X1, Matieland 7602, South Africa. ${ }^{2}$ Institut für Spezielle Botanik und Botanischer Garten, Johannes Gutenberg-Universität, Anselm-Franz-von-Bentzelweg 9a, 55099 Mainz, Germany. ${ }^{3}$ Department of Botany and Zoology, University of Stellenbosch, Private Bag X1, Matieland 7602, South Africa. ${ }^{4}$ INRES Pflanzenzüchtung, Rheinische Friedrich-Wilhelms-Universität Bonn, Katzenburgweg 5, 53115 Bonn, Germany.

Received: 7 May 2016 Accepted: 8 September 2016 Published online: 17 September 2016

\section{References}

1. Myers N, Mittermeier RA, Mittermeier CG, da Fonseca GA, Kent J. Biodiversity hotspots for conservation priorities. Nature. 2000;403(6772):853-8.

2. Hughes C, Eastwood R. Island radiation on a continental scale: exceptional rates of plant diversification after uplift of the Andes. Proc Natl Acad Sci U S A. 2006;103(27):10334-9.

3. Richardson JE, Pennington RT, Pennington TD, Hollingsworth PM. Rapid diversification of a species-rich genus of Neotropical rainforest trees. Science. 2001;293(5538):2242-5.

4. Valente LM, Savolainen V, Vargas P. Unparalleled rates of species diversification in Europe. Proc R Soc B. 2010;277(1687):1489-96.

5. Klak C, Reeves G, Hedderson TA. Unmatched tempo of evolution in Southern African semi-desert ice plants. Nature. 2004:427(6969):63-5.

6. Goldblatt P, Manning JC. Plant diversity of the Cape region of southern Africa. Ann Missouri Bot Gard. 2002;89(2):281-302.

7. Linder HP. The radiation of the Cape flora, southern Africa. Biol Rev. 2003; 78(4):597-638.

8. Oliver EGH: Ericaceae. In: Plants of the Greater Cape Floristic Region, Volume 1: The Core Cape Flora. Edited by Manning JC, Goldblatt P, vol. 29. Pretoria: South African National Biodiversity Institute (SANBI Publishing); 2012: 482-511.

9. Hedberg $O$. Vegetation belts of the East African mountains. Svensk Bot Tidsk. 1951:45:140-202.

10. Pirie MD, Oliver EGH, Bellstedt DU. A densely sampled ITS phylogeny of the Cape flagship genus Erica L. suggests numerous shifts in floral macromorphology. Mol Phylogenet Evol. 2011;61(2):593-601.

11. Van der Niet T, Pirie MD, Shuttleworth A, Johnson SD, Midgley JJ. Do pollinator distributions underlie the evolution of pollination ecotypes in the Cape shrub Erica plukenetii? Ann Bot. 2014:113(2):301-16.

12. Mugrabi de Kuppler AL, Fagúndez J, Bellstedt DU, Oliver EGH, Léon J, Pirie MD. Testing reticulate versus coalescent origins of Erica lusitanica using a species phylogeny of the northern heathers (Ericeae, Ericaceae). Mol Phylogenet Evol. 2015;88:121-31.

13. Bellstedt DU, Pirie MD, Visser JC, de Villiers MJ, Gehrke B. A rapid and inexpensive method for the direct PCR amplification of DNA from plants. Amer J Bot. 2010;97(7):e65-68.

14. Taberlet P, Gielly L, Pautou G, Bouvet J. Universal primers for amplification of three non-coding regions of chloroplast DNA. PI Mol Biol. 1991;17(5):1105-9.

15. Shaw J, Lickey EB, Schilling EE, Small RL. Comparison of whole chloroplast genome sequences to choose noncoding regions for phylogenetic studies in angiosperms: the tortoise and the hare III. Amer J Bot. 2007;94(3):275-88. 
16. Wiens JJ, Fetzner JW, Parkinson CL, Reeder TW. Hylid frog phylogeny and sampling strategies for speciose clades. Syst Biol. 2005;54(5):778-807.

17. Maddison WP, Maddison DR. Mesquite: a modular system for evolutionary analysis. Version 3.04 In.: Available from http://mesquiteproject.org; 2015.

18. Vaidya G, Lohman DJ, Meier R. SequenceMatrix: concatenation software for the fast assembly of multi-gene datasets with character set and codon information. Cladistics. 2011;27(2):171-80.

19. Lanfear R, Calcott B, Ho SYW, Guindon S. PartitionFinder: combined selection of partitioning schemes and substitution models for phylogenetic analyses. Molec Biol Evol. 2012;29(6):1695-701.

20. Stamatakis A. RAxML-VI-HPC: maximum likelihood-based phylogenetic analyses with thousands of taxa and mixed models. Bioinformatics. 2006; 22(21):2688-90.

21. Stamatakis $A$, Hoover $P$, Rougemont J. A rapid bootstrap algorithm for the RAxML web servers. Syst Biol. 2008;57(5):758-71.

22. Pirie MD. Phylogenies from concatenated data: Is the end nigh? Taxon. 2015;64(3):421-3.

23. Drummond AJ, Suchard MA, Xie D, Rambaut A. Bayesian Phylogenetics with BEAUti and the BEAST 1.7. Molec Biol Evol. 2012;29(8):1969-73.

24. Tamura K, Battistuzzi FU, Billing-Ross P, Murillo O, Filipski A, Kumar S. Estimating divergence times in large molecular phylogenies. Proc Natl Acad Sci U S A. 2012;109(47):19333-8.

25. Schwery O, Onstein RE, Bouchenak-Khelladi Y, Xing Y, Carter RJ, Linder HP. As old as the mountains: the radiations of the Ericaceae. New Phytol. 2015; 207(2):355-67.

26. Popp M, Mirré V, Brochmann C. A single Mid-Pleistocene long-distance dispersal by a bird can explain the extreme bipolar disjunction in crowberries (Empetrum). Proc Natl Acad Sci USA 2011;108:6520-5.

27. Dupont LM, Linder HP, Rommerskirchen F, Schefuß E. Climate-driven rampant speciation of the Cape flora. J Biogeogr. 2011;38(6):1059-68.

28. Rambaut A, Suchard MA, Xie D, Drummond AJ. Tracer v1.6, 2014. Available from http://beast.bio.ed.ac.uk/Tracer.

29. Nylander JAA, Wilgenbusch JC, Warren DL, Swofford DL. AWTY (are we there yet?): a system for graphical exploration of MCMC convergence in Bayesian phylogenetics. Bioinformatics. 2008;24(4):581-3.

30. Magallón S, Sanderson MJ. Absolute diversification rates in angiosperm clades. Evolution. 2001;55(9):1762-80.

31. Harmon LJ, Weir JT, Brock CD, Glor RE, Challenger W. GEIGER: investigating evolutionary radiations. Bioinformatics. 2008;24(1):129-31.

32. Linder HP. The evolution of African plant diversity. Front. Ecol. Evol. 2014;2: 38. doi:10.3389/fevo.2014.00038.

33. Linder HP, Antonelli A, Humphreys AM, Pirie MD, Wüest RO. What determines biogeographical ranges? Historical wanderings and ecological constraints in the danthonioid grasses. J Biogeogr. 2013;40(5):821-34.

34. Valente LM, Reeves G, Schnitzler J, Mason IP, Fay MF, Rebelo TG, Chase MW, Barraclough TG. Diversification of the African genus Protea (Proteaceae) in the Cape biodiversity hotspot and beyond: equal rates in different biomes. Evolution. 2010;64(3):745-60.

35. FitzJohn RG. Diversitree: comparative phylogenetic analyses of diversification in R. Methods Ecol Evol. 2012;3(6):1084-92.

36. Rabosky DL. Automatic detection of key innovations, rate shifts, and diversity-dependence on phylogenetic trees. PLOS ONE. 2014;9(2):e89543.

37. Rabosky DL, Grundler M, Anderson C, Shi JJ, Brown JW, Huang H, Larson JG. BAMMtools: an R package for the analysis of evolutionary dynamics on phylogenetic trees. Methods Ecol Evol. 2014;5(7):701-7.

38. Plummer M, Best N, Cowles K, Vines K. CODA: convergence diagnosis and output analysis for MCMC. R News. 2006:6(1):7-11.

39. Verboom GA, Archibald JK, Bakker FT, Bellstedt DU, Conrad F, Dreyer LL, Forest F, Galley C, Goldblatt P, Henning JF, et al. Origin and diversification of the Greater Cape flora: ancient species repository, hot-bed of recent radiation, or both? Mol Phylogenet Evol. 2009:51(1):44-53.

40. Valente LM, Vargas P. Contrasting evolutionary hypotheses between two mediterranean-climate floristic hotspots: the Cape of southern Africa and the Mediterranean Basin. J Biogeogr. 2013;40(11):2032-46.

41. Rabosky DL. Extinction rates should not be estimated from molecular phylogenies. Evolution. 2010;64(6):1816-24.

42. Davis M, Midford P, Maddison W. Exploring power and parameter estimation of the BiSSE method for analyzing species diversification. BMC Evol Biol. 2013;13(1):38

43. Hughes $C E$, Atchison GW. The ubiquity of alpine plant radiations: from the Andes to the Hengduan Mountains. New Phytol. 2015;207(2):275-82.
44. Zachos J, Pagani M, Sloan L, Thomas E, Billups K. Trends, rhythms, and aberrations in global climate 65 Ma to present. Science. 2001;292:686-93.

45. Marlow JR, Lange CB, Wefer G, Rosell-Mele A. Upwelling intensification as part of the Pliocene-Pleistocene climate transition. Science. 2000;290(5500):2288.

46. Bytebier B, Antonelli A, Bellstedt DU, Linder HP. Estimating the age of fire in the Cape flora of South Africa from an orchid phylogeny. Proc R Soc B. 2011;278:188-95.

47. Coetzee JA, Rogers J. Palynological and lithological evidence for the miocene palaeoenvironment in the Saldanha region (South Africa). Palaeogeog Palaeoclim Palaeoecol. 1982;39(1):71-85.

48. Van Wilgen BW, Higgins KB, Bellstedt DU. The role of vegetation structure and fuel chemistry in excluding fire from forest patches in the fire-prone fynbos shrublands of South Africa. J Ecol 1990;78:210-222.

49. Brown N, Kotze G, Botha P. The promotion of seed germination of Cape Erica species by plant-derived smoke. Seed Sci Technol. 1993;21(3):573-80.

50. Ojeda F. Biogeography of seeder and resprouter Erica species in the Cape Floristic Region-Where are the resprouters? Biol J Linn Soc. 1998;63(3):331-47.

51. Cowling RM, Proches S, Partridge TC. Explaining the uniqueness of the Cape flora: incorporating geomorphic evolution as a factor for explaining its diversification. Mol Phylogenet Evol. 2009;51(1):64-74.

52. Hoffmann V, Verboom GA, Cotterill FPD. Dated plant phylogenies resolve neogene climate and landscape evolution in the Cape Floristic Region. PLOS ONE. 2015;10(9):e0137847

53. Verboom GA, Bergh NG, Haiden SA, Hoffmann V, Britton MN. Topography as a driver of diversification in the Cape Floristic Region of South Africa. New Phytol. 2015;207(2):368-76.

54. Goldblatt P. An analysis of the flora of Southern Africa: its characteristics, relationships, and origins. Ann Missouri Bot Gard. 1978;65:369-436.

55. Goldblatt P. Floristic diversity in the Cape Flora of South Africa. Biodiv Cons. 1997;6(3):359-77.

56. Jansson $R$, Dynesius $M$. The fate of clades in a world of recurrent climatic change: Milankovitch oscillations and evolution. Annu Rev Ecol Syst. 2002;33:741-77.

57. Ellis AG, Verboom GA, Van der Niet T, Johnson SD, Linder HP. Speciation and extinction in the Greater Cape Floristic Region. In: Allsopp N, Colville JF, editors. Fynbos: Ecology, Evolution, and Conservation of a Megadiverse Region. Verboom GA: Oxford University Press; 2014. p. 119-41.

58. Johnson SD. The pollination niche and its role in the diversification and maintenance of the southern African flora. Philos Trans Roy Soc Ser B. 2010; 365(1539):499-516.

59. Van der Niet T, Johnson SD, Linder HP. Macroevolutionary data suggest a role for reinforcement in pollination system shifts. Evolution. 2006;60(8): 1596-601.

60. Van der Niet T, Johnson SD. Patterns of plant speciation in the Cape floristic region. Mol Phylogenet Evol. 2009;51(1):85-93.

61. Warren B, Bakker F, Bellstedt D, Bytebier B, Claszen-Bockhoff R, Dreyer L, Edwards D, Forest F, Galley C, Hardy C, et al. Consistent phenological shifts in the making of a biodiversity hotspot: the Cape flora. BMC Evol Biol. 2011; 11(1):39.

62. Schnitzler J, Barraclough TG, Boatwright JS, Goldblatt P, Manning JC, Powell MP, Rebelo T, Savolainen V. Causes of plant diversification in the Cape biodiversity hotspot of South Africa. Syst Biol. 2011;60(3):343-57.

63. Cowling RM, Potts AJ, Bradshaw PL, Colville J, Arianoutsou M, Ferrier S, Forest F, Fyllas NM, Hopper SD, Ojeda F, et al. Variation in plant diversity in mediterranean-climate ecosystems: the role of climatic and topographical stability. J Biogeogr. 2015;42(3):552-64.

64. Linder HP, Hardy CR. Evolution of the species-rich Cape flora. Philos Trans Roy Soc Ser B. 2004;359(1450):1623-32.

65. Richardson JE, Weitz FM, Fay MF, Cronk QCB, Linder HP, Reeves G, Chase MW. Rapid and recent origin of species richness in the Cape flora of South Africa. Nature. 2001;412:181-3.

66. Mummenhoff K, Al-Shehbaz IA, Bakker FT, Linder HP, Mühlhausen A. Phylogeny, morphological evolution, and speciation of endemic Brassicaceae genera in the Cape Flora of South Africa. Ann Missouri Bot Gard. 2005;92(3):400-24.

67. Linder HP. Plant species radiations: where, when, why? Philos Trans Roy Soc Ser B. 2008:363(1506):3097-105 